\title{
FINANÇAS PESSOAIS NA PALMA DA MÃO: UM RELATO DE EXPERIÊNCIA
}

\section{ARTIGO ORIGINAL}

WATAYA, Roberto Sussumu ${ }^{1}$

FRAUCHES, Patricia ${ }^{2}$

BERGAMO, Andressa Ferreira ${ }^{3}$

WATAYA, Roberto Sussumu. FRAUCHES, Patricia. BERGAMO, Andressa Ferreira. Finanças pessoais na palma da mão: um relato de experiência. Revista Científica Multidisciplinar Núcleo do Conhecimento. Ano 05, Ed. 07, Vol. 05, pp. 109-124. Julho de 2020. ISSN: 2448-0959, Link de acesso: https://www.nucleodoconhecimento.com.br/tecnologia/financas-pessoais

\section{RESUMO}

O Projeto Gestão Financeira na Palma da Mão, foi elaborado visando a conscientização do tema sobre finanças para os graduando do Centro Universitário Adventista de São Paulo campus São Paulo - UNASP/SP, e da comunidade do entorno, pois entende-se que é um tema assaz importante para o futuro destes jovens

${ }^{1}$ Doutor em Educação Currículo PUC/SP; Mestre em Educação USF - Bragança Pta; Mestre Educação Currículo PUC/SP; Bel Direito UBC - Mogi das Cruzes/SP; Tecnólogo em Rede de Computador- UNASP/SP campus SP; Tecnólogo Sistemas para Internet- UNASP/EC- campus Engenheiro Coelho/SP. Licenciatura em Matemática- UNASP/SP - campus SP.

${ }^{2}$ Mestre em Ciências Contábeis - Fundação Escola de Comércio Álvares Penteado FECAP.

${ }^{3}$ Especialista MBA Gestão de Risco e Compliance - Faculdade Trevisan- São Paulo/SP. 
universitários. O objetivo deste estudo foi formar indivíduos mais conscientes e responsáveis quanto ao uso do dinheiro, proporcionando uma mudança no comportamento e atitudes financeiras para que se obtenha resultados efetivos na vida social e profissional. Este estudo apresentou os resultados da nona edição do projeto de 2018, que iniciou em 2010, os dados foram coletados na UNASP/SP. As atividades consistiram em palestras sobre o tema em questão e aplicação de atividades objetivando conscientizar e conhecer como está sua saúde financeira, além disso, foram utilizados os aplicativos Mobills, GuiaBolso e Realcash, permitindo aos participantes "conhecerem" e se familiarizarem, para depois optar por um deles, como ferramenta de controle de suas finanças pessoais. O desempenho "em grau de facilidade" dos participantes com os aplicativos tiveram o seguinte resultados com Mobills 85\%; GuiaBolso 90\% e RealCash 75\%, desse resultado o aplicativo GuiaBolso foi o destaque para os participantes. Assim, podemos afirmar que, grande parte dos alunos concluíram os estudos de maneira satisfatória as sete etapas. Para as considerações finais, podemos afirmar que educação financeira aliada aos recursos tecnológicos com aplicativos próprios, resultou em uma conscientização significativa dos jovens em busca de maiores conhecimentos sobre finanças, a fim de poderem fazer melhores escolhas relacionadas ao dinheiro, a curto, médio e longo prazo.

Palavras-chave: Educação Financeira, aplicativos de finanças, Unasp.

\section{INTRODUÇÃO}

$\mathrm{Na}$ vida acadêmica, o perfil do jovem universitário é caracterizado pelo imediatismo e rapidez nas buscas pelas informações, por meio de diferentes tipos de mídias eletrônicas. Dessa forma, as pessoas necessitam interagir com as novas configurações sociais, que influenciam diretamente as relações pessoais, o ambiente de trabalho, a vida profissional e a social. Os avanços tecnológicos e a sociedade atual, promovem uma sociedade mais imediatista e consumista diante da grande quantidade de ofertas e facilidades para a aquisição e o consumo. Esse contexto, requer da população uma postura de um saber mais crítico e consciente nas escolhas, nas definições de metas e prioridades nas diversas questões da vida, e especialmente na organização financeira (PRADO, 2015). 
Além disso, a educação financeira promove nos indivíduos uma postura mais segura, mais assertiva e um cidadão mais integrado. Assim, com esse estudo, busca-se mostrar a importância das finanças pessoais para preparar os cidadãos e cidadãs a conquistarem uma estabilidade financeira saudável, cuja condição possibilite a realizar o planejamento de curto e de longo prazo, e também e melhorar o desempenho escolar desses jovens graduandos.

Tendo seu início em 2010, o projeto está na décima edição, sendo apresentado neste relato os dados referentes ao período de 2019. No contexto em que vive o Brasil, com uma grande parcela dos jovens sem trabalho remunerado, e a parcela de jovens empregados estão "afundando" cada vez mais em dívidas, comprometendo uma aposentadoria tranquila e segura.

Neste contexto, o objetivo geral deste estudo foi formar indivíduos mais conscientes e responsáveis quanto ao uso do dinheiro, proporcionando uma mudança no comportamento e atitudes financeiras para que se obtenha resultados efetivos na vida social e profissional. E os objetivos específicos foram: possibilitar aos jovens e adultos/família por meio de processo educativo, novos conhecimentos e ferramentas práticas para uma autonomia financeira.

Este estudo está dividido em seis seções, iniciando com esta Introdução, na segunda seção Trabalhos relacionados, em seguida Educação Financeira, na terceira seção o Projeto Gestão Financeira na Palma da Mão. Na quinta seção a Análise dos Dados e finalmente a sexta seção, as Considerações Finais.

\section{TRABALHOS RELACIONADOS}

Dentre os trabalhos usados para auxiliar o entendimento do conceito de educação financeira, destacamos os seguintes trabalhos científicos, iniciando com Barbosa, Sena, Cardoso, Vieira Sá e Costa Filho (2017), fizeram um estudo sobre Finanças Pessoais com alunos do curso de Administração de um IES Pública, e o objetivo da pesquisa consistiu em conhecer o comportamento financeiro dos estudantes de Administração de uma IES pública em relação às Finanças Pessoais. 
Nessa mesma linha de raciocínio, Medeiros e Lopes (2014) pesquisaram sobre o conhecimento financeiro dos graduandos do curso de Ciências Contábeis em um município do estado do Rio Grande do Sul. E o trabalho teve como objetivo analisar o comportamento desse grupo, sobre o tema finanças pessoais.

Trabalhando nesse mesmo tema, Andrade e Lucena (2018), fizeram um trabalho de verificação da relação entre o nível de educação financeira de diferentes grupos acadêmicos com as características individuais e o comportamento financeiro desses alunos.

Sob um viés perceptivo, Silva, C. L. e Silva, J.G. (2019) Educação Financeira e o Comportamento do Consumidor: um estudo com jovens de Ituiutaba/MG. O estudo teve como objetivo verificar se o nível de educação financeira de jovens exerce influência em seu processo de decisão de compra de smartphones.

Já os autores Compara, Vieira, Costa e Fraga (2015) trabalharam sobre o tema inadimplência, e o objetivo desses autores foi identificar os motivos que os levaram a essas situações, e quais soluções eles encontraram?

Destacamos dois livros, o primeiro de autoria de Kiyocera e Lechter (2000), que acredita que as escolas deveriam ensinar os alunos a terem conhecimentos suficientes para uma autonomia financeira. Pois o contexto descrito pelos autores, os jovens recebem uma mesada e cartão de crédito, sem se preocupar no uso sábio do dinheiro. Dessa forma, eles agem de acordo com a pressão do grupo, comprar o smartphone de última geração, roupas de grifes e assim por diante. Nesse contexto, os autores trabalham o livro Pai Rico e Pai Pobre, onde o primeiro ensina suas crianças a pensarem em valorizar seu dinheiro, enquanto o segundo, por temer os riscos prefere o silêncio sobre o assunto.

O segundo livro "Me Poupe", da autora Nathalia Arcuri que trabalha a fobia provocada pelo dinheiro, fato que anula o relacionamento das pessoas com esse tema: dinheiro. E como proposta em seu livro ela sugere os dez passos para a vida financeira de 
sucesso. Também ajuda a identificar os problemas e vícios que bloqueiam o seu enriquecimento e a encontrar o caminho do sucesso (ARCURI, 2018).

Destacaremos apenas um vídeo (2019), onde dois rappers e um economista, trabalham com a moçada da periferia, tendo como foco, desmistificando o mercado financeiro (EXAME-ABRIL[4], 2019).

\section{EDUCAÇÃO FINANCEIRA}

Neste estudo, adotaremos o conceito de "educação financeira" o mesmo utilizado pela OCDE - Organização para Cooperação e Desenvolvimento Econômico, que afirma, "

à educação financeira é o processo mediante o qual os indivíduos e as sociedades melhoram a sua compreensão em relação aos conceitos e produtos financeiros, de maneira que, com informação, formação e orientação, possam desenvolver os valores e as competências necessários para se tornarem mais conscientes das oportunidades e riscos neles envolvidos e, então, poderem fazer escolhas bem informadas, saber onde procurar ajuda e adotar outras ações que melhorem o seu bem-estar. Assim, contribuir de modo mais consistente para a formação de indivíduos e sociedades responsáveis, comprometidos com o futuro (PREVIC, s/d).

O tema Educação Financeira como proposto neste projeto, busca uma melhoria na qualidade de vida dos jovens graduandos no presente e no futuro, proporcionando assim segurança material necessária para conquistar uma vida confortável e revestido de garantias em casos de emergências e imprevistos. Este estudo não consiste apenas em fazer economias, cortar gastos, aprender a poupar e valorizar o dinheiro, que para uma boa gestão de finanças é necessário que se tenha conhecimento sobre finanças, pois caso contrário a incorreta administração dos recursos financeiros poderão incorrer na maior crise financeira.

Diante de uma realidade, onde a política econômica do país não vem correspondendo às expectativas de que haveria uma consolidação no processo de retomada econômica, e com perspectivas otimistas dos consumidores. Apesar dos juros menores e a inflação dentro da meta, e o desemprego ainda é elevado, fato que inibe a capacidade de gastos das famílias[5]. Além disso, uma pesquisa realizada pela 
Confederação Nacional de Dirigentes Lojistas - CNDL em conjunto com a SERASA Serviço de Proteção ao Crédito, mostrou que volume de inadimplência cresceu 0,9\% no primeiro semestre de 2019 em comparação ao mesmo período de 2018 (CNDL, 2019).

Ainda nessa mesma linha de raciocínio, a Confederação Nacional do Comércio de Bens, Serviços e Turismo - CNC, que é uma entidade sindical de um dos principais setores da economia do Brasil, que juntas essas categorias respondem por cerca de $1 / 4$ do Produto Interno Bruto - PIB brasileiro e geram aproximadamente 25,5 milhões de empregos diretos e formais. A CNC, tem feito pesquisas que diagnosticam a saúde financeira das famílias brasileiras, e a PEI[6] (2019) conforme Tabela 1, verificamos o nível de endividamento em \% em relação ao total das famílias.

Tabela 1 - Nível de endividamento familiar

Nivel de endividamento (\% em relação ao total de famílias)

\begin{tabular}{|c|c|c|c|}
\hline Categoria & $\begin{array}{c}\text { Dezembro de } \\
\text { Muito endividado }\end{array}$ & $\begin{array}{c}\text { Novembro de } \\
\mathbf{2 0 1 8}\end{array}$ & $\begin{array}{c}\text { Dezembro de } \\
\mathbf{2 0 1 9}\end{array}$ \\
\hline Mais ou menos endividado & $12,4 \%$ & $14,4 \%$ & $14,5 \%$ \\
\hline Pouco endividado & $23,1 \%$ & $22,9 \%$ & $23,3 \%$ \\
\hline Não tem dívidas desse tipo & $24,3 \%$ & $27,8 \%$ & $27,8 \%$ \\
\hline Não sabe & $39,9 \%$ & $34,7 \%$ & $34,2 \%$ \\
\hline Não respondeu & $0,2 \%$ & $0,2 \%$ & $0,1 \%$ \\
\hline
\end{tabular}

Fonte: PEIC, 2019

Nessa tabela, percebemos que a proporção das famílias que se declaram muito endividadas teve um aumento, entre os meses de novembro de 2019 e dezembro 2019, de 14,4\% do total de famílias. E na comparação anual, dezembro de 2018 a dezembro de 2019, aumentou 2,1\%, e ainda nesse período, a parcela que declarou "estar Mais ou menos endividado", evoluiu de $23,1 \%$ para $23,3 \%$, e finalmente a parcela Pouco endividado passou de $24,3 \%$ para $27,8 \%$, um aumento de $3,5 \%$. 
Gráfico 1 - Principais tipos e dívidas

\section{Principais Tipos de dívida}

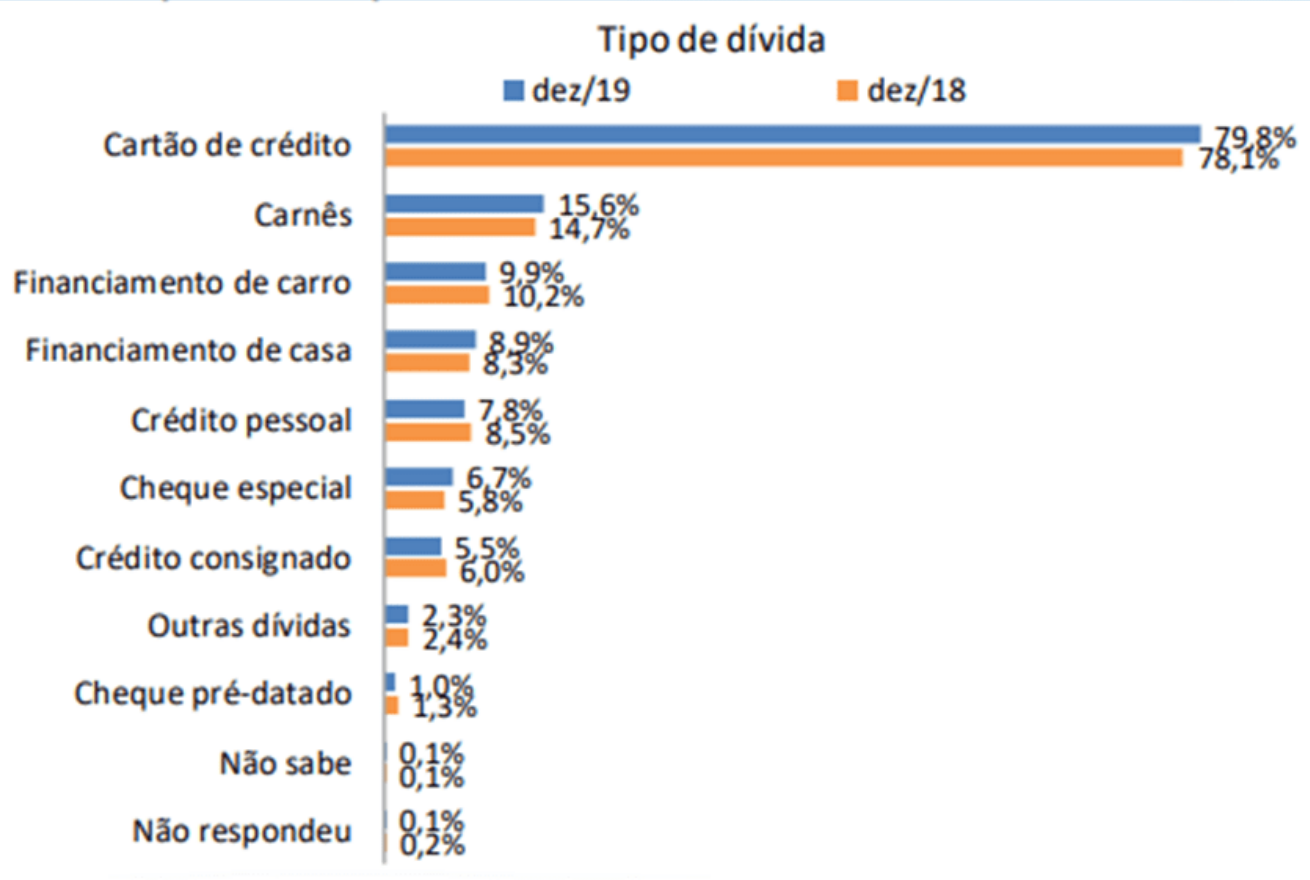

Fonte: PEIC, 2019

No gráfico 1 - sobre Tipos de dívidas, a pesquisa mostra que aumentou em dezembro de 2019, alcançando 79,8\% para a dívida do tipo Cartão de Crédito; o Cheque Especial 6,7\%;Cheque Pré-datado 1,0\%; Crédito Consignado 5,5\%; Crédito Pessoal 7,8\%; Carnês 15,6\%; Financiamento de Carro 9,9\%; Financiamento de Casa 8,9\%; Outras dívidas 2,3\%. Segundo a pesquisa, a tendência de alta do endividamento está associada à ampliação do mercado de crédito ao consumidor, e a melhora recente no mercado de trabalho principalmente no emprego formal, aliada à redução das taxas de juros e a redução do custo do crédito.

\section{PROJETO GESTÃO FINANCEIRA NA PALMA DA MÃO}

No Brasil, verificamos em nossa sociedade de consumo, uma verdadeira batalha fratricida, como se não bastasse à defasagem salarial, o alto custo de vida nos deparamos ainda com a pressão do consumismo gerado pela sociedade capitalista, que nos impele a comprar mesmo quando não haja recursos, por meio de cartão de 
crédito, cheques especiais e endividamento junto às financeiras, levando assim, a um desequilíbrio das finanças pessoais e familiares.

O que há realmente por trás deste desequilíbrio é a falta de educação financeira. Não aprendemos a viver de acordo com a renda que conseguimos gerar. A preocupação com a qualidade de vida de nossa sociedade é parte importante do projeto que um grupo de alunos dos cursos de Ciências Contábeis; Ciências/Engenharia da Computação e Tecnologia em Análise, propõe a realizar para a comunidade acadêmica.

Assim, como inúmeros trabalhadores, os jovens e adultos de nossa sociedade andam as voltas com as dificuldades geradas pela crise econômica. Dificuldades estas que podem gerar ansiedade, desconcentração, baixa produtividade, acidentes em serviço, etc.

Em nossa convivência diária com essas pessoas das comunidades, muitos se queixam de que o salário não tem conseguido cobrir as despesas mensais. Estas reclamações podem ser indicadoras da dificuldade deles de viverem de acordo com a renda que consegue gerar, criando um círculo vicioso e ao invés dessas pessoas apresentarem uma atitude pró-ativa, aumentando a renda ou reduzindo a despesa, passa a reclamar do seu salário e do governo.

Diante desses problemas enfrentados pelos jovens e graduandos, refletem a dura realidade resultados da falta de conhecimento, da desorganização financeira, do estresse causado por endividamentos, entre outros, que nos levou a propor esse estudo.

\subsection{A EXPERIÊNCIA}

O Centro Universitário Adventista de São Paulo (UNASP/SP[7]), ciente do seu papel no bairro de Capão Redondo apoia essa iniciativa de promover a educação financeira para os seus alunos, que precisam aprender seus conceitos que ajudam na utilização dos seus recursos disponíveis de maneira adequada, e racionalmente a fazer as 
melhores escolhas com o seu rico dinheirinho, dessa forma garantir o futuro e estar preparado para situações de emergências e auxiliar no alcance dos objetivos da vida.

Este projeto teve a duração de abril a 12 dezembro de 2018, e foi realizado presencialmente, na sala 14A do prédio Universitário da UNASP campus São Paulo. Ele foi realizado na forma de aulas práticas, usando Smartphone com Android com aplicativos de Finanças, durante oito meses, totalizando 20 (vinte) domingos, resultando em 60 (sessenta) horas aulas. Nesse período foram contemplados os seguintes conteúdos.

Etapa-1 - O Orçamento de uma Família; Brasileira: Razões para estudar; Finanças Pessoais e Tecnologia;

Etapa-2 - Crises Financeiras: como fugir delas? Conhecendo as Despesas, Dicas e como fazer seu Controle Financeiro. Trabalhando com Dispositivo móvel- Aplicativo1: Mobills[8]

Etapa-3 - Orçamentos Familiares: mudanças de padrão. O segredo do sucesso: Planejar- passo a passo para seu planejamento; Trabalhando com Dispositivo móvelAplicativo-1: Mobills

Etapa-4 - Você sabe quanto gasta? Mudando o presente e construindo o futuro: crise financeira- como vencer a crise financeira? Cuidado: razões que nos levam ao endividamento; Trabalhando com Dispositivo móvel- Aplicativo-1: Mobills

Etapa-5 - Gastar muito é uma doença? Como trabalhar com "compulsão para gastar?"; Trabalhando com Dispositivo móvel- Aplicativo-2: Guia Bolso[9]

Etapa-6 - Conhecendo os Bancos: Santander, Bradesco, Itaú, BB etc. Ensinar seus filhos a juntar dinheiro. Trabalhando com Dispositivo móvel- Aplicativo-2: GuiaBolso

Etapa-7: Práticas Tecnológicas: Planilha eletrônica e o software livre: Realcash.

Este estudo foi um trabalho experimental e exploratório, baseado no método quantitativo e qualitativo. A amostra constituiu-se em 160 alunos de ambos os sexos, 
que candidataram para participar do estudo. Para participar deste projeto, o pré requisito foi ser universitário.

Os candidatos foram entrevistados pelo coordenador do projeto para diagnosticar o motivo do seu interesse, o grau de conhecimento financeiro, avaliar e selecionar, ao todo foram 150 universitários que participaram da pesquisa. Os outros 10 candidatos desistiram pelo fato do projeto acontecer aos domingos.

\section{ANÁLISE DOS DADOS}

Como resultado das entrevistas dadas ao coordenador, foi construído o perfil dos alunos que participaram do projeto, o gráfico 2- Idade dos participantes. Percebemos a predominância de um grupo jovem, assim distribuído: 65\% na faixa etária de 16 a 25 anos; $20 \%$ de 26 a 30 anos; $13 \%$ de 31 a 40 anos e apenas $2 \%$ de 41 a 60 anos.

Gráfico 2- Idade dos Participantes

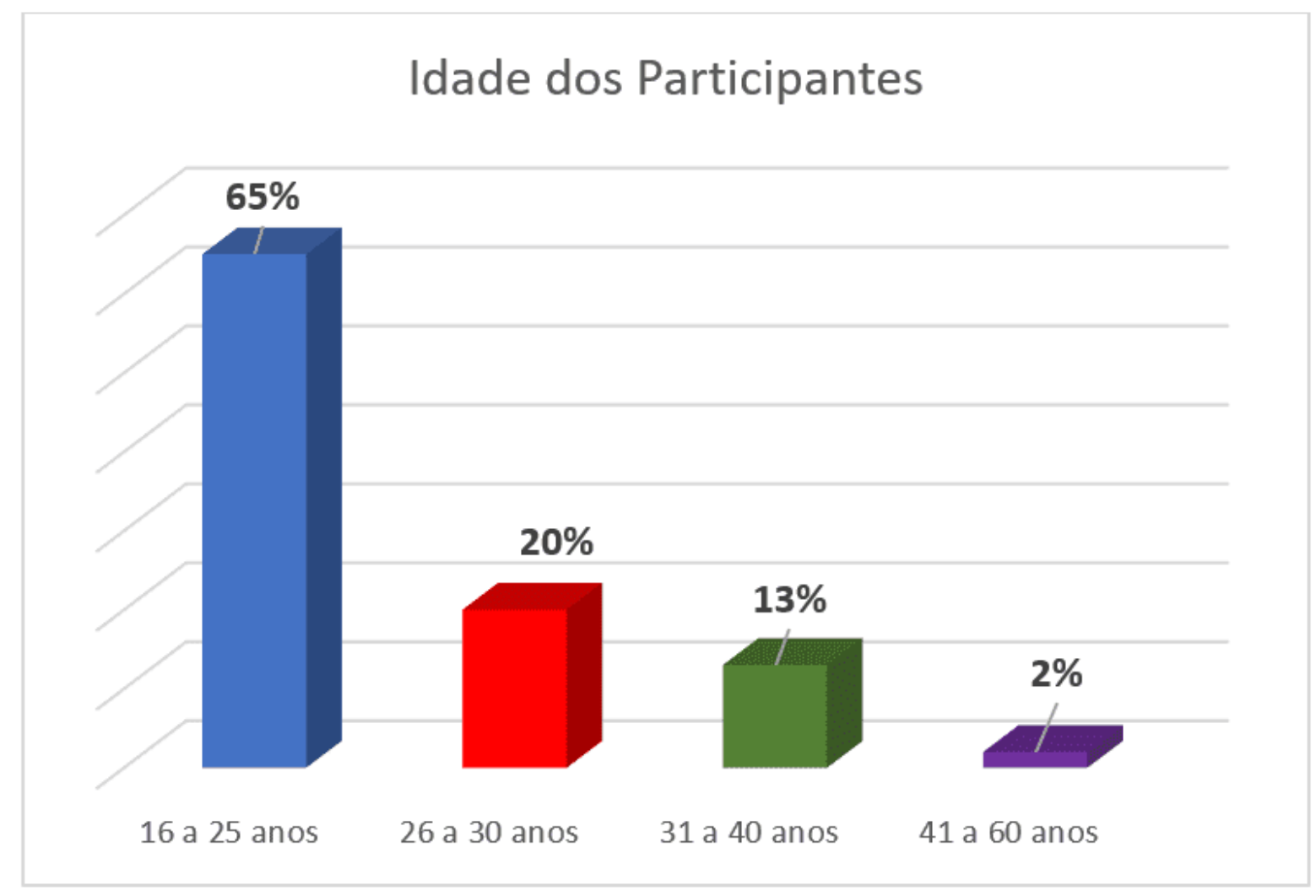

Fonte: Autor (2019) 
A seguir, vamos conhecer qual a predominância dos cursos dos participantes através do no gráfico 3. A participação dos alunos por cursos, tiveram este comportamento: 23\% do curso Ciências Contábeis; 19\% Administração; 17\% do curso de Análise e Desenvolvimento de Sistemas; 15\% Ciências da Computação; 4\% Biologia e 3\% para cada um dos sete cursos a seguir: Publicidade e Propaganda, Arquitetura, Psicologia, Enfermagem, Nutrição, Fisioterapia, Engenharia da Computação; e finalmente com 1\% Educação Física.

Gráfico 3- Cursos dos Participantes

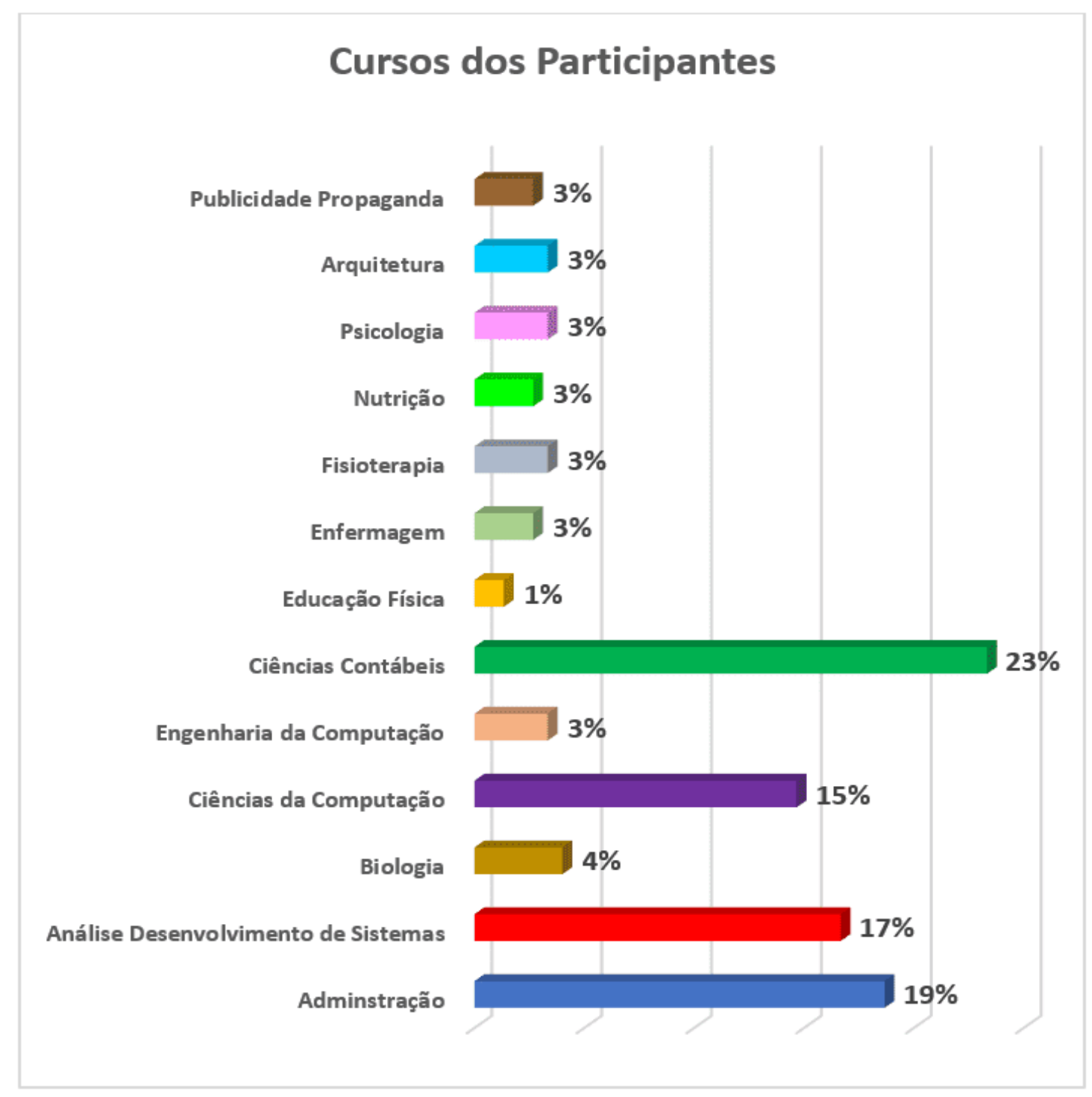

Fonte: Autor (2019) 
O desenvolvimento das etapas do projeto foram de inteira responsabilidade do professor coordenador e também dos monitores voluntários, ao todo foram 12, onde cada um procurou fazer o melhor para alcançar os objetivos estabelecidos pelo projeto. Este trabalho também contou com a participação do pastor do campus, para os momentos de reflexão de 15 minutos.

A proposta deste trabalho foi descrever a prática curricular baseada no Projeto Gestão Financeira na Palma da Mão, que focou quatro pontos da educação financeira, 1) Possibilitar aos jovens e adultos/família por meio de processo educativo novos conhecimentos e ferramentas práticas para a auto gestão responsável das finanças de sua família, promovendo assim o aumento de seu bem-estar e qualidade de vida. 2) Sensibilizar as pessoas/famílias por meio de processo educativo a otimizar a sua vida financeira; 3) Experimentar novas atitudes e comportamentos na reestruturação de padrões financeiros disfuncionais; 4) Aumentar a produtividade e reduzir os problemas gerados do descontrole financeiro.

Os resultados do projeto referente aos oito meses de trabalho e o desenvolvimento das sete etapas de conteúdos programáticos, foi considerado bom, apesar do período do curso ser considerado curto pelos participantes, apesar dos vinte encontros dominicais. A participação dos alunos nesse estudo foi marcada pela importância nos conteúdos apresentados, e o resultado de seus desempenhos consta no gráfico 3. 
Gráfico 4- Desempenho com os aplicativos financeiros

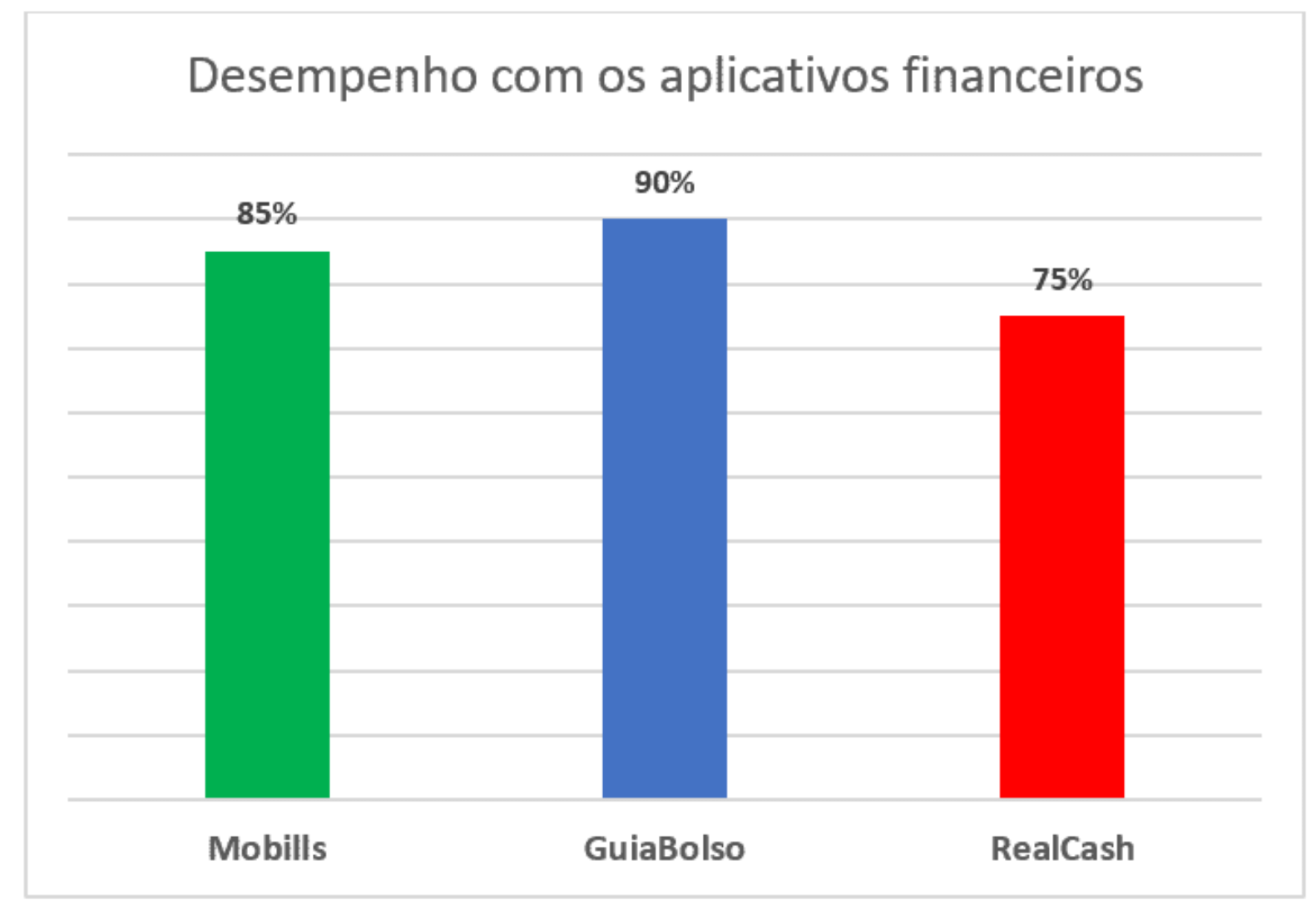

Fonte: Autor (2019)

No gráfico 4, observamos dados de maneira sintetizados referentes às atividades dos participantes em um período de oito meses de aula expositiva seguida da prática, utilizando o Smartphone com os aplicativos. O desempenho "em grau de facilidade" dos participantes com os aplicativos tiveram o seguinte resultados com Mobills 85\%; GuiaBolso $90 \%$ e RealCash 75\%. Desse resultado, o aplicativo GuiaBolso foi o destaque para os usuários. $\mathrm{E}$ finalmente podemos afirmar que, grande parte dos alunos concluíram os estudos de maneira satisfatória as sete etapas.

\section{CONSIDERAÇÕES FINAIS}

O projeto, serviu para os participantes e a todos os envolvidos a terem um aprofundamento teórico-prático em assuntos sobre a educação financeira, ou seja, "Gestão Financeira na Palma da Mão". Após finalizar esse projeto, foi possível concluir 
que sua realização se deu de forma satisfatória e destaca a sua importância, pois esse tema é atual e de extrema necessidade não apenas aos universitários, mas a sociedade de um modo geral.

Mesmo em uma roda de alunos, percebemos como eles enfrentam com muitas dificuldades a melhor forma de administrar as suas finanças, e o reflexo disso é um grande número de endividados, assim este projeto que foca a educação financeira torna-se imprescindível a todos. Assim, podemos assegurar que a educação financeira ajuda a gerir de forma inteligente os recursos financeiros, e também a melhorar as condições de vida, garantindo um futuro tranquilo, tendo mais segurança em situações de emergências e também nas realizações dos sonhos. Por outro lado, o desequilíbrio financeiro atinge a família toda, provocando situações de estresses, desentendimento familiares e em alguns casos com fim trágico.

Finalmente, esse projeto de educação financeira aliada aos recursos tecnológicos com aplicativos próprios, resultou em uma demanda de jovens em busca de maiores conhecimentos a fim de poder fazer melhores escolhas relacionadas ao dinheiro, nos três tipos de prazo: longo, médio e curto. Assim, a iniciativa do curso de Ciências Contábeis com apoio da UNASP/SP em implantar este projeto de extensão é importante, e os objetivos foram alcançados. A metodologia e os conteúdo abordados tiveram um resultado positivo e um grande número de participantes, pois proporcionaram à maioria deles um conhecimento sólido e suficiente para uma boa gestão financeira.

\section{REFERÊNCIAS}

ANDRADE, J.P.; LUCENA, W.G.L. EDUCAÇÃO FINANCEIRA: uma análise de grupos acadêmicos. 2018. Disponível no site: periodicos.pucminas.br/index.php/economiaegestao/article/view/10121. Acesso em 21/06/2019.

ARCURI, N. Me Poupe: Dez passos para nunca mais faltar dinheiro no seu bolso. São Paulo: Editora Sextante, 2018. 
BARBOSA, C. P.; SENA, R, R.; CARDOSO, E.A.M.; VIEIRA SÁ, L.Y.B.; COSTA FILHO, J.P. FINANÇAS PESSOAIS: um estudo com alunos do curso de Administração de uma IES Pública. Disponível no site: http://oldror.lbp.world/UploadedData/2953.pdf acesso em 20/06/2019.

CAMPARA, J.P.; VIEIRA, K.M.; COSTA, V.M.F.; FRAGA, L.S. Dilema dos Inadimplentes: antecedentes e consequentes do "nome sujo". 2015. Disponível no site: https://www.redalyc.org/pdf/4717/471755315006.pdf acesso em 22/06/2019.

CNDL. Confederação Nacional dos Dirigentes Lojistas. Inadimplência do consumidor desacelera e cresce $0,9 \%$ no primeiro semestre de 2019 , aponta indicador CNDL/SPC Brasil. 2019. Disponível no site: https://site.cndl.org.br/inadimplencia-do-consumidordesacelera-e-cresce-09-no-primeiro-semestre-de-2019-aponta-indicador-cndlspcbrasil/ Acesso em 10/09/2019.

EXAME-ABRIL. Canal no YouTube ensina a educação financeira para jovens da periferia. 2019. Disponível no site: https://exame.abril.com.br/seu-dinheiro/canal-noyoutube-ensina-educacao-financeira-para-jovens-da-periferia/ Acesso em 04/12/2019.

KIYOCERA, R.; LECHTER, S.L. Pai Rico Pai Pobre: o que os ricos ensinam a seus filhos sobre dinheiro. 24를 ed. Rio de Janeiro: Editora Campus, 2000.

MEDEIROS, F.S.B.; LOPES, T.A.M. FINANÇAS PESSOAIS: um estudo com alunos do curso de Ciências Contábeis de uma IES privada de Santa Maria/RS. 2014. Disponível no site: www.portaldeperiodicos.unisul.br/index.php/EeN/article/view/1966. Acesso em 20/06/2019.

PEIC - Pesquisa de Endividamento e Inandimplência do Consumidor. 2019. Disponível no site: http://www.cnc.org.br/editorias/economia/pesquisas/pesquisa-deendividamento-e-inadimplencia-do-consumidor-peic-3 Acesso em 05/01/2020.

PRADO, A.B. Educação Financeira: a visão de jovens universitários sobre finanças familiares.

2015.

Disponível

no

site: 
https://tede2.pucsp.br/bitstream/handle/1135/1/Andre\%20Brisola\%20Brito\%20Prado. pdf acesso em 12/09/2019.

PREVIC, Superintendência Nacional de Previdência Complementar. O que é Educação Financeira. s/d. Disponível no site: http://www.previc.gov.br/regulacao/educacao-previdenciaria/educacao-financeira-eprevidenciaria/o-que-e-educacao-financeira. Acesso em 11/09/2019.

SILVA, C.L.; SILVA, J.G. Educação Financeira e o Comportamento do Consumidor: um estudo de caso com jovens de Ituiutaba/MG. 2019 Disponível no site: https://repositorio.ufu.br/bitstream/123456789/23578/3/EducacaoFinanceiraComport amento.pdf. Acesso em 21/06/2019.

\section{APÊNDICE - REFERÊNCIAS DE NOTA DE RODAPÉ}

4. Para conhecer, segue o link do vídeo https://exame.abril.com.br/seu-dinheiro/canalno-youtube-ensina-educacao-financeira-para-jovens-da-periferia/

5. José Cesar da Costa- Presidente da Confederação Nacional de Dirigentes Lojistas

6. PEI - Pesquisa Nacional de Endividamento e Inadimplência do Consumidor, é apurada mensalmente pela CNC desde janeiro de 2010. Os dados são coletados em todas as capitais dos Estados e no Distrito Federal, com cerca de 18 mil consumidores. Dessas informações coletadas, são apurados importantes indicadores como, Percentual de consumidores endividados, Percentual de consumidores com contas em atraso, Percentual de consumidores que não terão condições de pagar suas dívidas, Tempo de endividamento e Nível de comprometimento da renda (PEI, 2019).

7. UNASP/SP está localizada a $9 \mathrm{~km}$ de Santo Amaro e a $23 \mathrm{~km}$ do centro de São Paulo, seu endereço é Estrada de Itapecerica, no 5859, Jardim IAE no bairro de Capão Redondo, subdistrito de Santo Amaro, região sul da cidade de São Paulo. 
8. O Mobills é um dos aplicativos de finanças pessoais mais completos. $O$ app apresenta diversas ferramentas para proporcionar o controle de gastos para o seu usuário. O Mobills é ideal para quem deseja substituir as planilhas por uma ferramenta bem mais intuitiva e fácil de ser usada. $\mathrm{O}$ app apresenta muitos recursos e permite grande agilidade no registro dos seus gastos mensais e diários. Com o objetivo de gear facilidade durante a leitura de dados, o aplicativo oferece gráficos interativos e também apresenta a sincronização com seu cartão de crédito, permitindo facilmente o controle de ganhos e gastos durante o mês. Ele é um Freemium cujo a versão paga é no formato de assinatura mensal. Um presente para você, use o código TOPINVEST20 e ganhe $20 \%$ de desconto na assinatura do Mobills; Gratuitamente o app já realiza comparativos anuais e mensais dos gastos indicando exatamente em qual categoria o usuário gastou mais do que deveria. Além de IOS, Android e Windows Phone o Mobills também está disponível na web. As informações que você cadastra nele são sincronizadas automaticamente na nuvem para manter a plataforma atualizada caso você queira ver em seu PC ou notebook. Disponível no site: https://www.topinvest.com.br/aplicativos-de-financas-pessoais-os-7-melhores/ acesso em 15/01/2018.

9. O GuiaBolso é um aplicativo com um bom diferencial que é o fato de fazer conexão com as suas contas bancárias. Ah, não se preocupe quanto a segurança do app pois o seu nível de segurança é altíssimo e suas contas não serão roubadas por terceiros. O app oferece segurança em nível bancário e tem mais de 3 milhões de usuários no brasil. O GuiaBolso pode ser utilizado para 3 finalidades: Controle financeiro automático; Empréstimos feitos com o juros mais baixo possível; Radar sobre o CPF; O controle financeiro do aplicativo permite que o usuário controle melhor as suas finanças além de permitir um melhor planejamento de suas contas futuras. No app há a função GuiaBolso empréstimo no qual você pode encontrar, contratar e acompanhar de forma $100 \%$ virtual as melhores ofertas de empréstimos disponibilizadas pelas instituições financeiras. Lá você encontra empréstimos pessoais com juros a partir de 2,8\% ao mês (atenção, não tome empréstimo sem antes ler o artigo sobre os tipos de crédito para pessoa física). Este app é 100\% gratuito disponível para IOS e Android. Ele entre em segundo lugar na lista dos melhores aplicativos de finanças pessoais 
justamente por suas funções extras de rastrear o CPF e encontrar os melhores empréstimos possíveis. Disponível no site: https://www.topinvest.com.br/aplicativosde-financas-pessoais-os-7-melhores/ acesso em 15/01/2018.

Enviado: Junho, 2020.

Aprovado: Julho, 2020. 